\title{
Communications
}

\section{Observation de sclérectasie dans un élevage de porc à Sotouboua, Togo}

Ph. Marchot 1
A. Vermeylen ${ }^{1}$
G. Hendrickx
P. Leroy ${ }^{2}$

MARCHOT (Ph.), VERMEYLEN (A.), HENDRICKX (G.), LEROY (P.). Observation de sclérectasie dans un élevage de porc à Sotouboua, Togo. Revue Élev. Méd. vét. Pays trop., 1992, 45 (3-4) : 227-228

Des cas de sclérectasie ont été décrits dans un élevage porcin à Sotouboua, Togo. Le virus de la peste porcine pourrait en être l'origine, la consanguinité étant un facteur prédisposant. Les éleveurs doivent rester vigilants. Mots clés : Porc - Pestivirus - Sclérectasie - Microphtalmie - Togn.

\section{Introduction}

Dans un élevage de porcs de race Large White, quatre sœurs ont été saillies par leur frère et fécondées en 1989 , 1990 et 1991. Ces truies ont donné naissance à quatre portées totalisant 22 porcelets normaux en octobre, novembre et décembre 1989 ; quatre porcelets sont morts au sevrage de diarrhée et les autres ont présenté une croissance normale. En juillet et août 1990, elles ont eu 28 porcelets dont 26 porteurs de malformations oculaires ; deux porcelets seulement se sont développés normalement. Par la suite, trois des quatre truies ont eu en mars et avril 1991 des portées de porcelets normaux (15 au total), et la quatrième a avorté ; parmi ces 15 , six sont morts avant, et au sevrage, et les autres ont été rapidement vendus par le propriétaire (tableau I).

TABLEAU I Résumé des observations effectuées dans l'élevage sur les porcelets en 1989, 1990 et 1991.

\begin{tabular}{|c|c|c|c|}
\hline Année & $\begin{array}{c}\text { Nombre } \\
\text { de porcelets }\end{array}$ & $\begin{array}{c}\text { Nombre } \\
\text { de porcelets } \\
\text { présentant des } \\
\text { malformations } \\
\text { oculaires }\end{array}$ & $\begin{array}{c}\text { Nombre } \\
\text { de porcelets } \\
\text { à croissance } \\
\text { normale }\end{array}$ \\
\hline 1989 & 22 & - & 18 \\
\hline 1990 & 28 & 26 & 2 \\
\hline 1991 & 15 & - & $9(?)$ \\
\hline
\end{tabular}
1. Food and Agriculture Organization (FAO), Via delle Terme di
Caracalla, 00100 Rome, Italie.

2. Université de Liège, Faculté de médecine vétérinaire, Service de biostatistique-informatique, B-1070 Bruxelles, Belgique.

Reçu le 27.8.1992, accepté le 23.3.1993.

\section{Observations cliniques et lésions}

Les anomalies oculaires qui ont été observées sont dues à un processus inflammatoire dans l'oeil lors du développement embryonnaire fœtal. L'inflammation des chambres, antérieure et postérieure, ainsi que de la rétine a provoqué une augmentation des liquides intra-oculaires et un amincissement de la cornée. Ces phénomènes ont entraîné soit de la sclérectasie, c'est-à-dire une formation kystique de la cornée débordant du globe (photo 1), soit au stade ultérieur, la crevaison de l'œil avant que le porcelet ne naisse. En effet, certains porcelets sont nés en présentant une cavité vide à la place du globe oculaire (phénomène différent de l'anophtalmie) (photo 2) ou en présentant de la phtysie du globe ; cette dernière était un amalgame de tout le contenu de l'œil, sans perforation, qui cliniquement ressemblait à de la microphtalmie. Tous les porcelets porteurs de telles lésions étaient soit aveugles, soit mal-voyants.

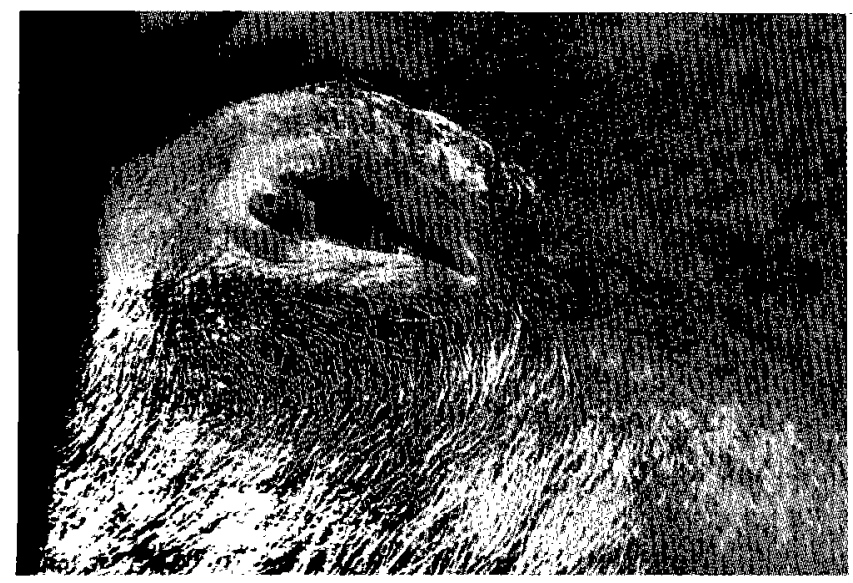

Photo I : Cas de sclérectasie avec formation kystique de la cornée et de la conjonctive.

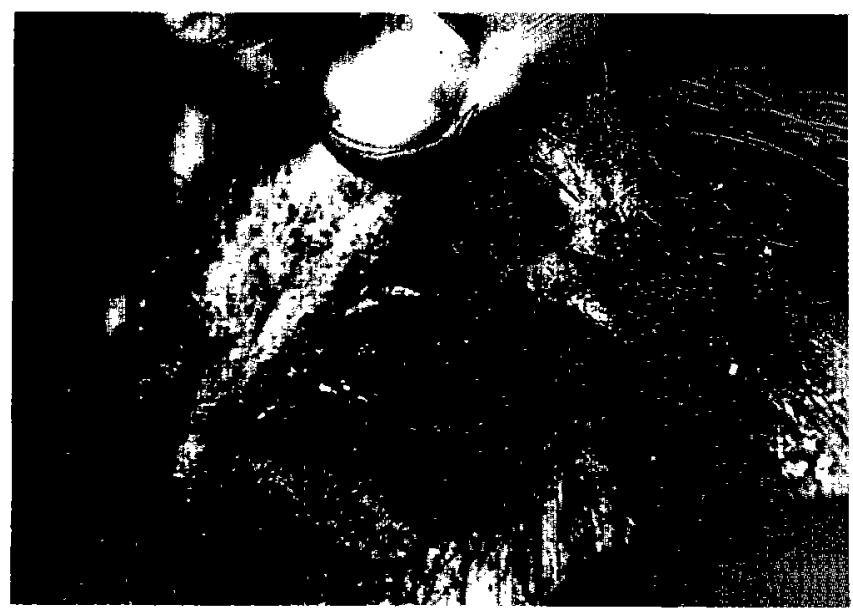

Photo 2 : Cas de sclérectasie au stade avancé (cavité vide à la place du globe oculaire). 


\section{Communications}

\section{Discussion}

Vingt-six porcelets au total sont nés avec des malformations oculaires. Quinze d'entre eux sont morts au cours de la première année : 2 , juste après la naissance et 13 pendant les 12 premiers mois, en présentant des anomalies de croissance et de la cachexie.

Les lésions observées ressemblent à de la microphtalmie dont la cause principale est la carence en vitamine A (2) ; mais les analyses des rations alimentaires des porcs qui ont été effectuées ont montré que celles-ci n'étaient carencées ni on vitamine A, ni en zinc (12 $000 \mathrm{UI}$ vit.A/kg, $200 \mathrm{mg} \mathrm{Zn/kg}$ de MS). De plus, les lésions dégénératives de l'avitaminose A n'ont pas le caractère inflammatoire de celles qui ont été décrites; une telle étiologie est donc improbable.

De telles malformations congénitales laissent supposer l'existence d'une prédisposition génétique révélée par le croisement frère/sœur qui a préparé le terrain au développement d'une réaction inflammatoire (7). Jusqu'ici, seuls les virus de la peste porcine classique ont été isolés d'une inflammation intra-utero dans l'œil foetal $(1,3,8)$. L'infection naturelle par le virus de la maladie d'Aujeszky ou pseudo-rage a entraîné de la cécité chez des porcs par atteinte dégénérative des cellules nerveuses de la rétine, suite à une inflammation qui s'était propagée, le long du nerf optique (5) ; mais une transmission fœtale n'a jamais été décrite (6). De plus, les kératoconjonctivites expérimentales produites par inoculation de lésions cornéennes avec ce même virus y restent confinées et régressent spontanément (9).

De même, les lésions cornéennes décrites jusqu'ici, dues à Mycoplasma hyorrhinis associé à Escherichia coli (4), au virus de l'influenza type A (10), à Chlamydia psittaci (11) ou à la pseudo-rage (9), et qui sont ici limitées à de la conjonctivite ou de la kératoconjonctivite ne sont pas dues à la transmission in utero des agents vecteurs. La transmission transplacentaire du virus de la peste porcine classique, dont la présence serait sporadique au Togo, est une hypothèse plausible.
Une enquête plus approfondie mérite d'être effectuée. Mais, lors de notre dernier passage, l'élevage avait fait l'objet d'un vide sanitaire et il ne nous a pas été possible de récolter les sérums qui auraient permis de confirmer nos suspicions.

Les élevages de la zone ont néanmoins été placés sous surveillance afin d'effectuer les prélèvements requis si de nouveaux cas se présentaient.

MARCHOT (Ph.), VERMEYLEN (A.), HENDRICKX (G.), LEROY (P.). Observation of sclerectasia in a pig farm, Sotouboua, Togo. Revue Élev. Méd. vét. Pays trop., 1992, 45 (3-4) : 227-228

Cases of sclerectasia were described in a pig farm, Sotouboua, Togo. The causative agent may be a pestivirus, on top of a predisposition revealed by consanguinity. Livestock owners should be kept aware. Key words : Pig Pestivirus - Sclerectasia - Microphtalmia - Togo.

\section{Bibliographie}

1. CARBREY (E.A.), STEWART (W.C.), YOUNG (S.H.). The changing picture of hog cholera : case studies. J.A.V.M.A., 1966, 149 (12) : 17201724.

2. HALE (F.). The relation of vitamin A to anophtalmia in pigs. Am. $J$. Ophtalmol., 1935, 18 : 1087-1093.

3. HARDING (J.D.), DONE (J.T.). Microphtalmia in piglets. Vet. Rec., $1956,68: 856-857$.

4. HOUSZKA (M.), PILASZEK (J.), BARTZAK (R.). Keratoconjonctivitis in mycoplasmosis in piglets. Medycyna Wet., 1979, 35 (10) : 598-600.

5. HOWARTH (J.A.), DE PAOLI (A.). An enzootic of pseudorabies in swine in California. Am. J. vet. Res., 1968, $152(8): 1114-1118$.

6. KLUGGE (J.P.), MARE (C.J.). Swine pseudorabies : abortion, clinical disease and lesions in pregnant gilts infected with pseudorabies virus. Am. J. vet. Res., 1974, 35 (7) : 911-915.

7. MANEELY (R.B.). Blindness in New-born pigs. Vet. Rec., 1951, 63 (23) : 398.

8. PLATEAU (E.), VANNIER (Ph.), TILLON (J.P.). A typical hog cholera infection : viral isolation and clinical study of in utero transmission. Am. $J$. vet. Res., 1980, 41 (12) : 2012-2015.

9. SCHNEIDER (W.J.), HOWARTH (J.A.). Clinical course and histopathologic features of pseudorabies virus-induced keratoconjonctivitis in pigs. Am. J. vet. Res., 1973, 34 (3) : 393-401.

10. STRAW (B.E.). Differential diagnosis of swine diseases. In $:$ LEMAN (A.D.), STRAW (B.E.), GLOCK (R.D.) et al. Diseases of swine. 6th ed.. $\Lambda$ mes, Iowa Statc University Press, 1986. Pp. 214-242.

11. TAYLOR (D.J.). Chlamydia. In : LEMAN (A.D.), STRAW (B.E.), GLOCK (R.D.) et al. Diseases of swine. 6th ed. Ames, Iowa State University Press, 1986. Pp. 630 633. 